\title{
The association between LncRNA HOTAIR and cancer lymph node metastasis and distant metastasis: a meta-analysis
}

\author{
Z. SUN, X.Y. WU, C.L. WU* \\ Department of breast and thyroid surgery, Tongde hospital of Zhejiang province, Hangzhou, 310012, China \\ ${ }^{*}$ Correspondence: $z j$ sltdwcl@163.com
}

Received January 14, 2017/ Accepted May 29, 2017

\begin{abstract}
HOTAIR has been reported to be associated with development and metastasis in different types of cancer. This metaanalysis collected all relevant articles and explored the correlation of HOTAIR with lymph node metastasis (LNM) and distant metastasis (DM). A literature collection was conducted by searching PubMed, Web of Science, Google Scholar and Cochrane Library (up to Sep 11, 2016). The odds ratio (OR) with 95\% confidence interval $(95 \% \mathrm{CI}$ ) was calculated to assess the association with strength. Nineteen studies were included in this study, with a total of 1874 patients. The study objects were all Asians. We found high HOTAIR expression in tumor tissues was significantly correlated with LNM and DM, and analysis showed a pooled OR of 3.18 (95\% CI: 2.10-4.81, p<0.00001) and 3.93 (95\% CI: 2.39-6.47, p<0.00001), respectively. HOTAIR may serve as a novel diagnostic biomarker for cancer metastasis.
\end{abstract}

Key words: HOTAIR, lymph node metastasis, distant metastasis, meta-analysis

Cancer has become a major cause of mortality, which is a serious threat to human health. There are estimated 14.1 million new cancer cases and 8.2 million cancer deaths worldwide [1]. Lymph node metastasis (LNM) and distant metastasis (DM) play important roles in the TNM classification system, which dictates the choice of therapy and predicts prognosis of cancer patients clinically. Most of the reports, however, were only talking about specific molecular markers for a particular tumor. A common molecular marker for predicting LNM and DM at the transcriptional level has not been elucidated.

Long non-coding RNAs (lncRNAs) are a group of RNAs which have a length of more than 200 nucleotides and do not participate in protein generation [2]. LncRNAs are involved in multiple processes of cancer development and progression, via chromosome remodeling, transcription and posttranscriptional processing [3].

LncRNA HOTAIR is transcribed from the antisense strand of the HOXC gene on chromosome 12q13.13, which has a length of 2158 nucleotides and has no protein-coding capacity [4]. Many studies have shown that HOTAIR is associated with the development and metastasis in different types of cancer, including breast cancer $[5,6]$, gastric cancer $[7,8]$, colorectal cancer [9], liver cancer [10], lung cancer [11], etc. We collected all relevant articles and conducted a meta-analysis to clarify the association between HOTAIR and cancer metastasis.

\section{Materials and methods}

Literature search. We searched relevant articles from the following electronic databases: PubMed, Web of science, Cochrane Library, and Google Scholar. The key word "HOTAIR" was used for search. The search was completed on Sep 11, 2016 and all non-English articles were excluded.

Inclusion and exclusion criteria. The following inclusion criteria were used: 1) articles investigating HOTAIR in any type of carcinoma; 2) the expression levels of HOTAIR in tissues of cancer patients were measured; 3 ) patients were grouped according to the expression levels of HOTAIR; 4) related clinicopathological parameters were described.

The following exclusion criteria were used: 1) articles were not related to carcinoma; 2) letters, expert opinions, case reports, editorials, and reviews; 3 ) studies with duplicate data; 4) studies without usable data.

Data extraction. Data from the eligible studies were extracted by two investigators (Sun Z, Wu XY) independently, according to the inclusion and exclusion criteria above. For disagreements, a consensus was reached by a third investigator ( $\mathrm{Wu} \mathrm{CL}$ ). The following information was 
recorded: the first author, year of publication, country of origin, tumor type, number of patients, number of patients with lymph node metastasis and distant metastasis in each group, detection method, cut-off definition.

Statistical analysis. Statistical analysis of OR for LNM and DM were performed using RevMan5.3 software. To assess the statistical heterogeneity among the included studies, the chi-square test and Higgins $\mathrm{I}^{2}$ statistics were used. When $\mathrm{p}$-values were less than 0.05 and/or $\mathrm{I}^{2}$ value greater than $50 \%$, indicating the presence of heterogeneity, the randomeffect model was used for analysis. Otherwise, the fixedeffect model was adopted. Meanwhile, we tried to minimize the influence of heterogeneity by classifying the studies into subgroups based on similar characteristic. The potential bias was evaluated using a "funnel plot". A p-value less than 0.05 was considered as statistically significant.

\section{Results}

Studies characteristic. As shown in Figure 1, a total of 19 articles were enrolled from a search of the above databases using the search strategy as described above [12-30]. The mean patient sample size was 98.6 (range 48 to 218). Twelve studies came from China, 4 from Japan, 2 from Korea, and 1 from India. All the study objects were Asians. Among these 19 studies, 4 focused on gastric cancer (GC), 3 on esophageal squamous cell carcinoma (ESCC), 3 on cervical cancer (CC), 2 on oral squamous cell carcinoma (OSCC), 2 on colorectal cancer (CRC), 1 on non-small cell lung cancer (NSCLC), 1 on hepatocellular carcinoma (HCC), 1 on nasopharyngeal carcinoma (NPC), 1 on breast cancer (BC), 1 on endometrial carcinoma (EC). All cancerous specimens were well preserved before RNA extraction. No patient received chemotherapy or radiotherapy before surgery except one study (Xu 2013), in which some patients received chemotherapy before surgery. All the diagnoses of LNM and DM were based on pathology.

In the 19 studies, nine methods were used to divide high HOTAIR expression group and low HOTAIR expression group: 1) the level of HOTAIR expression measured by qRT-PCR was normalized to glyceraldehyde-3-phosphate dehydrogenase(GAPDH), and the cut-off value was mean value of HOTAIR levels; 2) the level of HOTAIR expression measured by qRT-PCR was normalized to GAPDH, and the cut-off value was median value of HOTAIR levels; 3 ) the level of HOTAIR expression measured by qRT-PCR was normalized to GAPDH, and the cut-off value was HOTAIR/GAPDH ratio of $1.0 ; 4)$ the level of HOTAIR expression measured by qRT-PCR was normalized to GAPDH, and the cut-off value was HOTAIR/GAPDH ratio of 0.273 ; 5) the level of HOTAIR expression measured by qRT-PCR, and the cut-off value was 1.5 -fold the level in corresponding normal tissue; 6) the level of HOTAIR expression measured by qRT-PCR, and the cut-off value was 2 -fold the level in corresponding normal tissue; 7) the level of HOTAIR expression measured by qRT-PCR, and the cut-off value was 5-fold the level in corre- sponding normal tissue; 8) the level of HOTAIR expression measured by qRT-PCR was normalized to GAPDH, and the cut-off value was determined by receiver operating characteristics analyses with the Youden's index of 0.239 ; (9) the level of HOTAIR expression measured by in situ hybridization (ISH). The expression of HOTAIR was evaluated using the staining index (SI) and was scored as $0,1,2,3,4,6$ or 9 , and the expression levels of HOTAIR were defined as high $(\mathrm{SI} \geq 6)$ or low $(\mathrm{SI}<6)$. The main characteristics of the nineteen eligible studies for meta-analysis are summarized in Table 1.

Meta-analysis results - association between HOTAIR and LNM. Eighteen studies reported the number of patients with LNM based on different HOTAIR expression levels in a total of 1814 patients. The random-effects model was adopted as the significant heterogeneity $\left(\mathrm{I}^{2}=66 \%, \mathrm{p}<0.0001\right)$. Analysis showed a pooled OR of 3.18 with $95 \%$ CI $2.10-4.81$ $(\mathrm{p}<0.00001)$ (Figure 2). Through comparing the incidence of lymph node metastasis between high HOTAIR expression group and low HOTAIR expression group, we found that there was a significant difference in the incidence of lymph node metastasis between the two groups. Meanwhile, we performed sensitivity analysis by sequentially removing each eligible study, and the exclusion of any studies did not change OR significantly. We also performed a subgroup analysis by country and cancer type. As shown in Figure 3 and Figure 4, the result that a significant relation between HOTAIR high expression and lymph node metastasis was exhibited in any subgroup, and we found there was no apparent heterogeneity in the subgroup of gastrointestinal cancer when in other subgroups was.

To assess publication bias, the included studies were conducted using funnel plot, and each point represented a separate study (Figure 5). We found funnel plot was almost

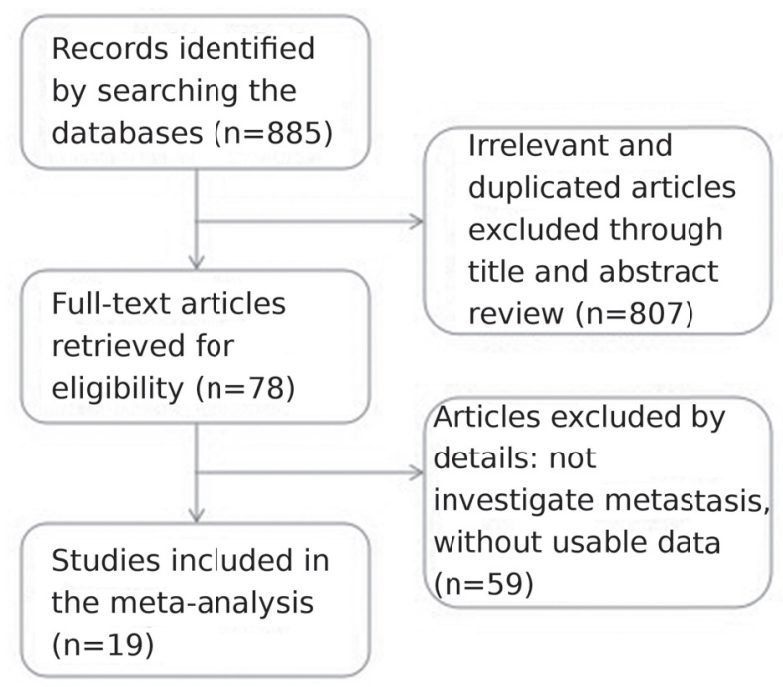

Figure 1. The flow diagram of the meta-analysis. 
Table 1. Characteristics of studies in this meta-analysis.

\begin{tabular}{|c|c|c|c|c|c|c|c|c|c|c|c|}
\hline \multirow[b]{2}{*}{ Author } & \multirow[b]{2}{*}{ Year } & \multirow[b]{2}{*}{ Country } & \multirow[b]{2}{*}{$\begin{array}{l}\text { Tumor } \\
\text { type }\end{array}$} & \multirow{2}{*}{$\begin{array}{l}\text { Sample } \\
\text { size }(n)\end{array}$} & \multicolumn{6}{|c|}{ HOTAIR expression } & \multirow[b]{2}{*}{ Method } \\
\hline & & & & & $\begin{array}{c}\text { High } \\
\text { expression }\end{array}$ & $\begin{array}{l}\text { High with } \\
\text { LNM }\end{array}$ & $\begin{array}{l}\text { High with } \\
\text { DM }\end{array}$ & $\begin{array}{c}\text { Low } \\
\text { expression }\end{array}$ & $\begin{array}{l}\text { Low with } \\
\text { LNM }\end{array}$ & $\begin{array}{l}\text { Low with } \\
\text { DM }\end{array}$ & \\
\hline Kogo & 2011 & Japan & CRC & 100 & 20 & 10 & 5 & 80 & 32 & 3 & qRT-PCR \\
\hline Endo & 2013 & Japan & GC & 68 & 43 & 29 & & 25 & 10 & & qRT-PCR \\
\hline $\mathrm{Ge}$ & 2013 & China & ESCC & 137 & 103 & 51 & & 34 & 13 & & qRT-PCR \\
\hline $\mathrm{Xu}$ & 2013 & China & GC & 83 & 56 & 52 & 7 & 27 & 17 & 2 & qRT-PCR \\
\hline Nakagawa & 2013 & Japan & NSCLC & 77 & 17 & 7 & & 60 & 10 & & qRT-PCR \\
\hline $\mathrm{Lv}$ & 2013 & China & ESCC & 93 & 48 & 29 & 10 & 45 & 17 & 4 & ISH \\
\hline $\mathrm{Nie}$ & 2013 & China & NPC & 160 & 91 & 76 & 32 & 69 & 58 & 13 & ISH \\
\hline Chen & 2013 & China & ESCC & 78 & 27 & 18 & & 51 & 8 & & qRT-PCR \\
\hline $\mathrm{Wu} \mathrm{ZH}$ & 2014 & China & CRC & 120 & 40 & 28 & 12 & 80 & 32 & 2 & qRT-PCR \\
\hline Okugawa & 2014 & Japan & GC & 150 & 77 & 59 & & 73 & 46 & & qRT-PCR \\
\hline Huang & 2014 & China & $\mathrm{CC}$ & 218 & 109 & 41 & & 109 & 6 & & qRT-PCR \\
\hline Yesim & 2014 & India & $\mathrm{BC}$ & 94 & 47 & 13 & & 47 & 19 & & ISH \\
\hline $\mathrm{He}$ & 2014 & China & $\mathrm{EC}$ & 87 & 63 & 11 & & 24 & 0 & & ISH \\
\hline Lee & 2014 & Korea & GC & 48 & 28 & 18 & & 20 & 7 & & qRT-PCR \\
\hline Qiu & 2014 & China & EOC & 64 & 32 & 20 & & 32 & 4 & & qRT-PCR \\
\hline Kim & 2014 & Korea & $\mathrm{CC}$ & 111 & 89 & 32 & & 22 & 3 & & qRT-PCR \\
\hline $\mathrm{Wu} \mathrm{J}$ & 2015 & China & OSCC & 50 & 25 & 14 & & 25 & 10 & & qRT-PCR \\
\hline Wu YS & 2015 & China & OSCC & 76 & 38 & 26 & & 38 & 8 & & qRT-PCR \\
\hline Gao & 2016 & China & $\mathrm{HCC}$ & 60 & 36 & & 12 & 24 & & 0 & qRT-PCR \\
\hline
\end{tabular}

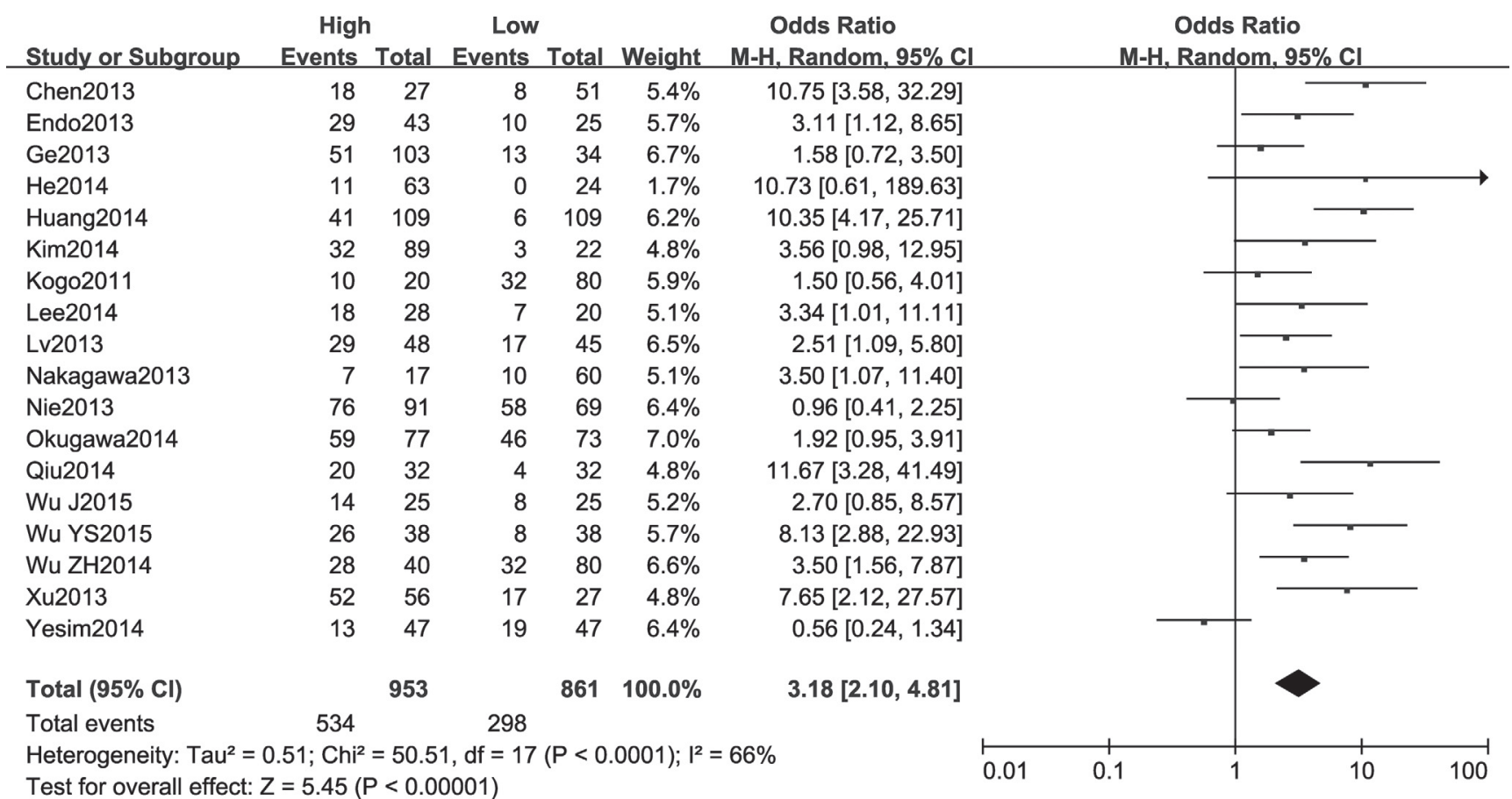

Figure 2. Forest plot for the association between HOTAIR expression levels and LNM.

symmetric. Thus, there was no apparent publication bias in this meta-analysis.

Association between HOTAIR and DM. Six studies reported the number of patients with DM based on different
HOTAIR expression levels in a total of 616 patients. The fixed-effects model was adopted as the significant heterogeneity $\left(\mathrm{I}^{2}=45 \%, \mathrm{p}=0.11\right)$. Analysis showed a pooled $\mathrm{OR}$ of 3.93 with 95\% CI 2.39-6.47 ( $<<0.00001$, Figure 6). Through 


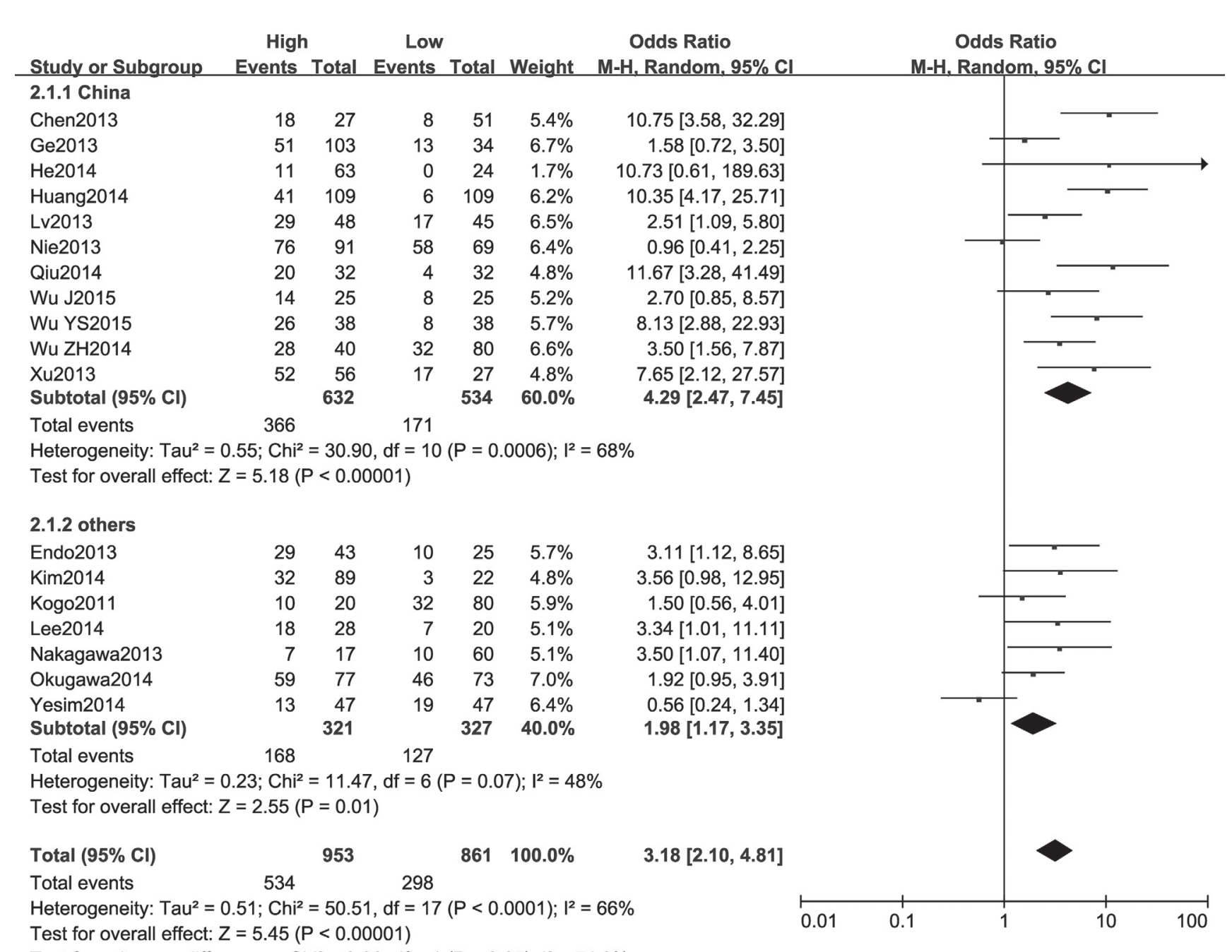

Figure 3. Forest plot for subgroup analysis of country (China and other countries).

comparing the incidence of distant metastasis between high HOTAIR expression group and low HOTAIR expression group, we found that there was a significant difference in the incidence of distant metastasis between the two groups. We used funnel plots to evaluate potential publication bias of the studies. As illustrated in Figure 7, the shape of the funnel plots was symmetrical which meant no apparent publication bias in this meta-analysis.

\section{Discussion}

HOTAIR is one of the well-studied long non-coding RNA. It interacts on 5 ' end with polycomb repressive complex 2 (PRC2) to remodel chromatin and silence HOX genes during embryonic development, whereas on 3' end HOTAIR interacts with histone demethylase [31-33]. HOTAIR affects the expression of genes through these functions. Previous studies have shown that HOTAIR expression was upregulated in cancerous tissues of different types of cancers, and overexpression of HOTAIR was associated with poor overall survival in cancer patients. Zhang et al. in a meta-analysis surveyed a total of 2033 patients from 19 studies [34]. This meta-analysis showed that HOTAIR was a predictive factor for poor prognosis in numerous cancers. Moreover, HOTAIR plays an important role in proliferation, invasiveness and metastasis of tumorigenic process.

In this meta-analysis, we found that high HOTAIR expression in tumor tissues was significantly correlated with LNM, and analysis showed a pooled OR of 3.18 (95\%CI: $2.10-4.81$, $\mathrm{p}<0.00001)$. Heterogeneity of the included 18 studies was significant $\left(\mathrm{I}^{2}=66 \%, \mathrm{p}<0.0001\right)$, so the random-effects model was adopted. Moreover, sensitivity analysis and subgroup analyses including country and cancer type were performed. Heterogeneity didn't change significantly when we removed 


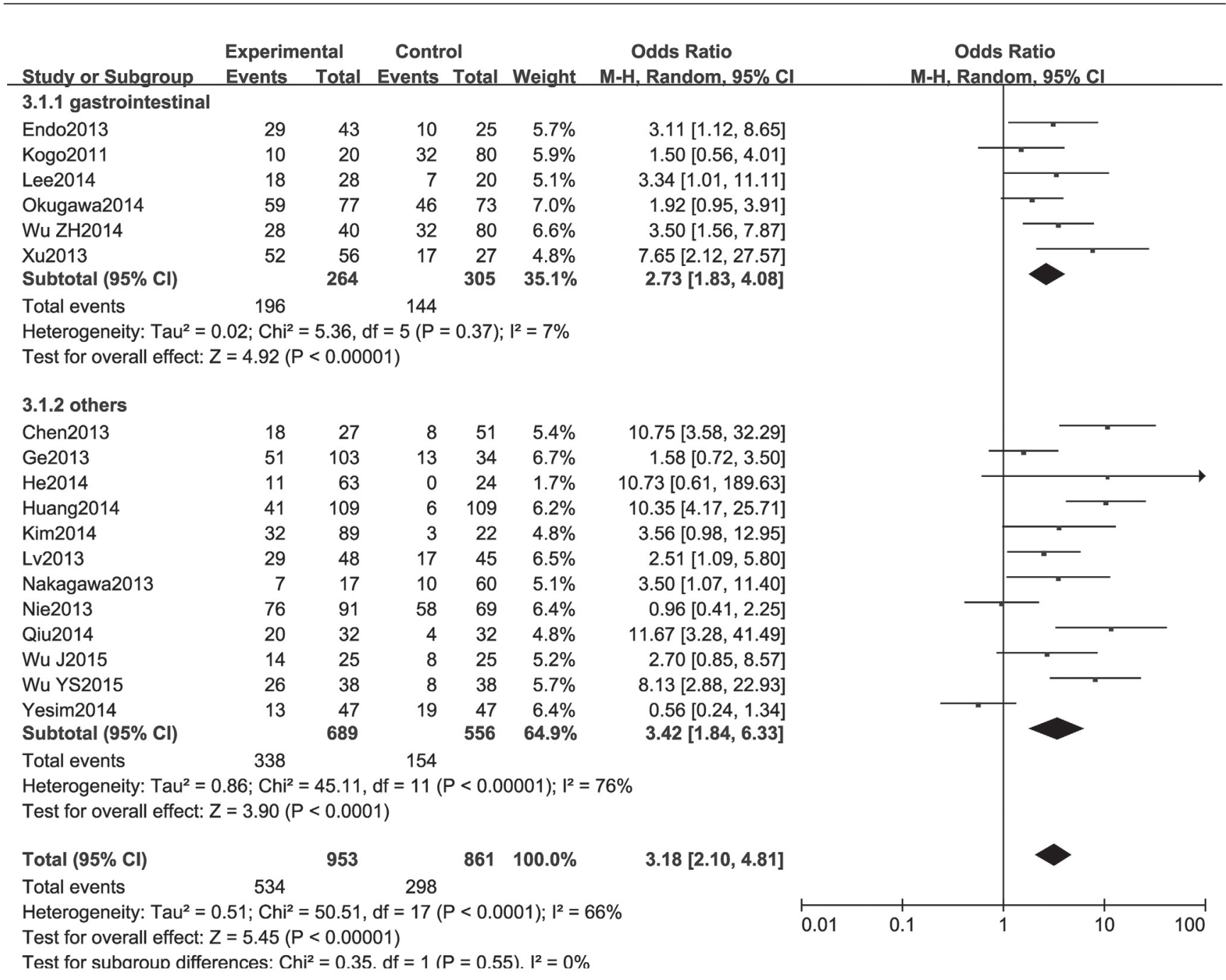

Figure 4. Forest plot for subgroup analysis of cancer type (gastrointestinal cancer and others).

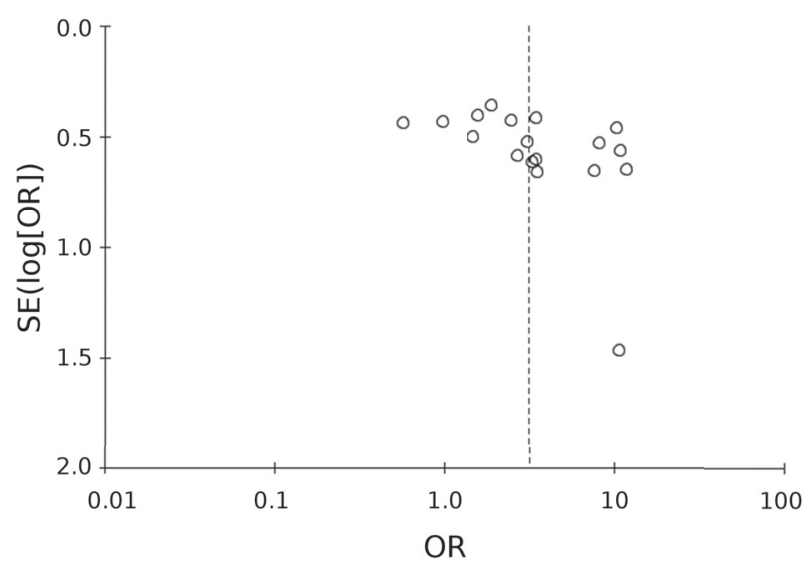

Figure 5. Funnel plots of the publication bias for 18 studies which reported HOTAIR and LNM. each study. Subgroup analysis showed that different countries and different types of cancer didn't change the overall result, and the predictive significance of HOTAIR in LNM was more significant in patients with gastrointestinal cancers than in those with other types of cancer. HOTAIR might be used as an independent diagnostic factor for lymph node metastasis of gastrointestinal cancers without heterogeneity.

Meanwhile, we found high HOTAIR expression was significantly correlated with DM, and analysis showed a pooled OR of 3.93 (95\%CI: 2.39-6.47, p<0.00001) without obvious heterogeneity $\left(\mathrm{I}^{2}=45 \%, \mathrm{p}=0.11\right)$. Therefore, the expression levels of HOTAIR can serve as a potential diagnostic factor for a variety of cancers.

Nevertheless, there were several limitations in our metaanalysis: 1) all of the included studies were retrospective studies, and it is necessary to conduct larger-size and better designed studies to confirm the results; 2) there was not a 


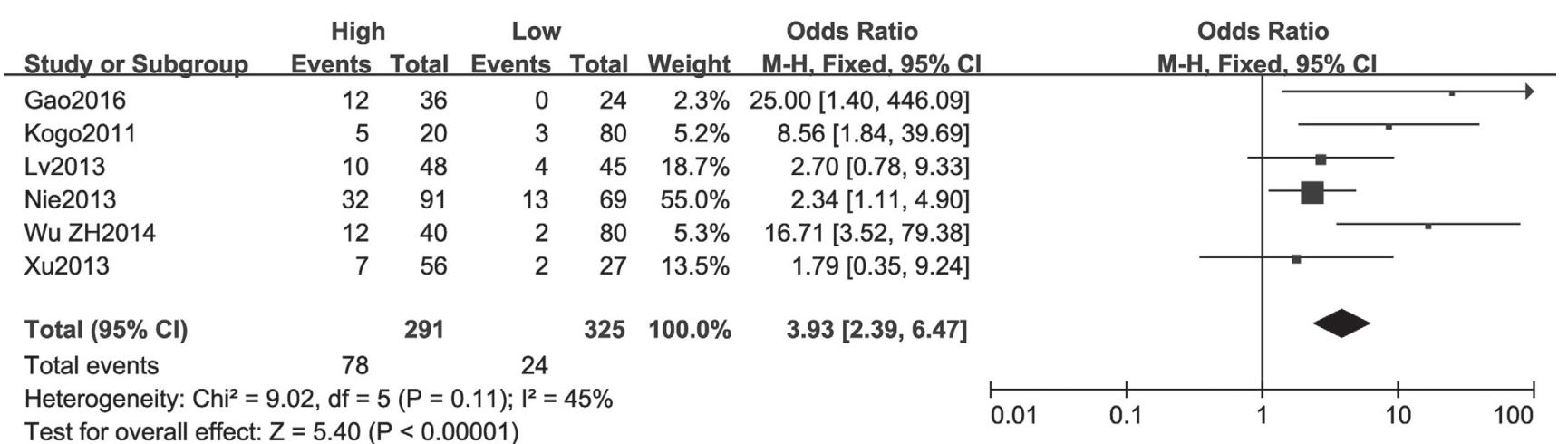

Figure 6. Forest plot for the association between HOTAIR expression levels and DM.

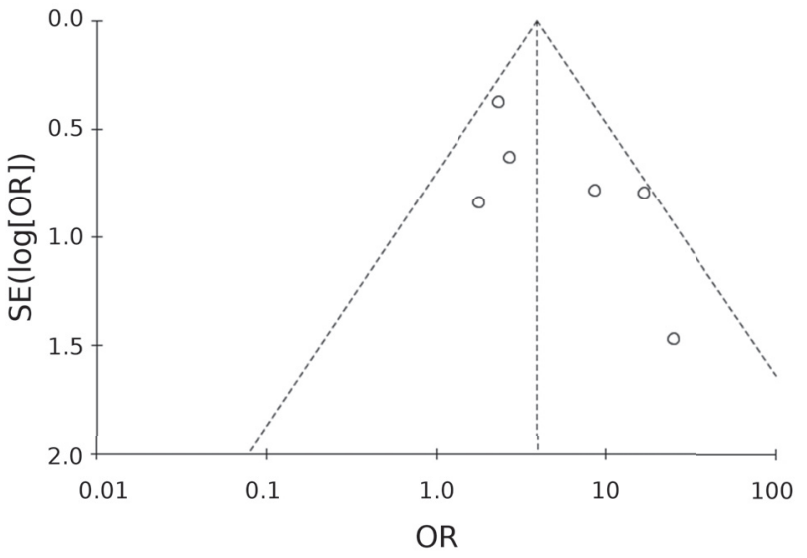

Figure 7. Funnel plots of the publication bias for 6 studies which reported HOTAIR and DM.

unified criterion for the cut-off value of HOTAIR expression; 3) patients included in our study were all Asians. Because of this, our finding may just represent patients from Asia. The study may achieve different outcomes from other continents; 4) we only included English language articles.

To sum up, our meta-analysis showed that the incidence of lymph node metastasis and distant metastasis in cancer patients with high HOTAIR expression was higher than that in those with low HOTAIR expression. HOTAIR could become a novel diagnostic biomarker for cancer metastasis.

\section{References}

[1] FERLAY J, SOERJOMATARAM I, DIKSHIT R, ESER S, MATHERS $\mathrm{C}$ et al. Cancer incidence and mortality worldwide: sources, methods and major patterns in GLOBOCAN 2012. Int J Cancer 2015; 136: E359-386. doi: 10.1002/ ijc. 29210

[2] CALEY DP, PINK RC, TRUJILLANO D, CARTER DR. Long noncoding RNAs, chromatin, and development. ScientificWorldJournal. 2010; 10: 90-102. doi: 10.1100/tsw.2010.7
[3] MERCER TR, DINGER ME, MATTICK JS. Long non-coding RNAs: insights into functions. Nat Rev Genet 2009; 10: 155-159. doi: 10.1038/nrg2521

[4] RINN JL, KERTESZ M, WANG JK, SQUAZZO SL, XU X et al. Functional demarcation of active and silent chromatin domains in human HOX loci by noncoding RNAs. Cell 2007; 129: 1311-1323. doi: 10.1016/j.cell.2007.05.022

[5] SORENSEN KP, THOMASSEN M, TAN QH, BAK M, COLD $S$ et al. Long non-coding RNA HOTAIR is an independent prognostic marker of metastasis in estrogen receptor-positive primary breast cancer. Breast Cancer Res Treat 2013; 142: 529-536. doi: 10.1007/s10549-013-2776-7

[6] BAYRAM S, SUMBUL A, DADAS E. A functional HOTAIR rs12826786 C > T polymorphism is associated with breast cancer susceptibility and poor clinicopathological characteristics in a Turkish population: a hospital-based case-control study. Tumour Biol 2016; 37: 5577-5584. doi: 10.1007/ s13277-015-4430-y

[7] HAJJARI M, BEHMANESH M, SADEGHIZADEH M, ZEINODDINI M. Up-regulation of HOTAIR long non-coding RNA in human gastric adenocarcinoma tissues. Med Oncol 2013; 30: 370. doi: 10.1007/s12032-013-0670-0

[8] EMADI-ANDANI E, NIKPOUR P, EMADI-BAYGI M, BIDMESHKIPOUR A. Association of HOTAIR expression in gastric carcinoma with invasion and distant metastasis. Adv Biomed Res 2014; 3: 135. doi: 10.4103/22779175.133278

[9] XUE Y, GU DY, MA GX, ZHU LJ, HUA QH et al. Genetic variants in lncRNA HOTAIR are associated with risk of colorectal cancer. Mutagenesis 2015; 30: 303-310. doi: 10.1093/mutage/geu076

[10] ISHIBASHI M, KOGO R, SHIBATA K, SAWADA G, TAKAHASHI Y et al. Clinical significance of the expression of long non-coding RNA HOTAIR in primary hepatocellular carcinoma. Oncol Rep 2013; 29: 946-950. doi: 10.3892/ or.2012.2219

[11] ONO H, MOTOI N, NAGANO H, MIYAUCHI E, USHIJIMA $\mathrm{M}$ et al. Long noncoding RNA HOTAIR is relevant to cellular proliferation, invasiveness, and clinical relapse in small-cell lung cancer. Cancer Med 2014; 3: 632-642. doi: $10.1002 /$ cam 4.220 
[12] KOGO R, SHIMAMURA T, MIMORI K, KAWAHARA K, IMOTO $S$ et al. Long Noncoding RNA HOTAIR Regulates Polycomb-Dependent Chromatin Modification and Is Associated with Poor Prognosis in Colorectal Cancers. Cancer Res 2011; 71: 6320-6326. doi: 10.1158/0008-5472.CAN-11-1021

[13] ENDO H, SHIROKI T, NAKAGAWA T, YOKOYAMA M, TAMAI $\mathrm{K}$ et al. Enhanced expression of long non-coding RNA HOTAIR is associated with the development of gastric cancer. PLoS One 2013; 8: e77070. doi: 10.1371/journal. pone. 0077070

[14] GE XS, MA HJ, ZHENG XH, RUAN HL, LIAO XY et al. HOTAIR, a prognostic factor in esophageal squamous cell carcinoma, inhibits WIF-1 expression and activates Wnt pathway. Cancer Sci 2013; 104: 1675-1682. doi: 10.1111/cas.12296

[15] XU ZY, YU QM, DU YA, YANG LT, DONG RZ et al. Knockdown oflong non-coding RNA HOTAIR suppresses tumor invasion and reverses epithelial-mesenchymal transition in gastriccancer.IntJBiolSci2013;9:587-597.doi:10.7150/ijbs.6339

[16] NAKAGAWA T, ENDO H, YOKOYAMA M, ABE J, TAMAI $\mathrm{K}$ et al. Large noncoding RNA HOTAIR enhances aggressive biological behavior and is associated with short disease-free survival in human non-small cell lung cancer. Biochem Biophys Res Commun 2013 436: 319-324. doi: 10.1016/j.bbrc.2013.05.101

[17] LV XB, LIAN GY, WANG HR, SONG EW, YAO HR et al. Long noncoding RNA HOTAIR is a prognostic marker for esophageal squamous cell carcinoma progression and survival. PLoS One 2013; 8: e63516. doi: 10.1371/journal. pone. 0063516

[18] NIE Y, LIU X, QU SH, SONG EW, ZOU H et al. Long noncoding RNA HOTAIR is an independent prognostic marker for nasopharyngeal carcinoma progression and survival. Cancer Sci 2013; 104: 458-464. doi: 10.1111/cas.12092

[19] CHEN FJ, SUN M, LI SQ, WU QQ, JI L et al. Upregulation of the long non-coding RNA HOTAIR promotes esophageal squamous cell carcinoma metastasis and poor prognosis. Mol Carcinog 2013; 52: 908-915. doi: 10.1002/mc.21944

[20] WU ZH, WANG XL, TANG HM, JIANG T, CHEN J et al. Long non-coding RNA HOTAIR is a powerful predictor of metastasis and poor prognosis and is associated with epithelial-mesenchymal transition in colon cancer. Oncol Rep 2014; 32: 395-402. doi: 10.3892/or.2014.3186

[21] OKUGAWA Y, TOIYAMA Y, HUR K, TODEN S, SAIGUSA $S$ et al. Metastasis-associated long non-coding RNA drives gastric cancer development and promotes peritoneal metastasis. Carcinogenesis 2014; 35: 2731-2739. doi: 10.1093/ carcin/bgu200

[22] HUANG L, LIAO LM, LIU AW, WU JB, CHENG XL et al. Overexpression of long noncoding RNA HOTAIR predicts a poor prognosis in patients with cervical cancer. Arch Gynecol Obstet 2014; 290: 717-723. doi: 10.1007/s00404-014-3236-2
[23] GOKMEN-POLAR Y, VLADISLAV IT, NEELAMRAJU Y, JANGA SC, BADVE S. Prognostic Impact of HOTAIR Expression is Restricted to ER-Negative Breast Cancers. Sci Rep 2015; 5: 8765. doi: 10.1038/srep08765

[24] HE X, BAO W, LI X, CHEN Z, CHE Q et al. The long noncoding RNA HOTAIR is upregulated in endometrial carcinoma and correlates with poor prognosis. Int J Mol Med 2014; 33: 325-332. doi: 10.3892/ijmm.2013.1570

[25] LEE NK, LEE JH, PARK CH, YU D, LEE YC et al. Long noncoding RNA HOTAIR promotes carcinogenesis and invasion of gastric adenocarcinoma. Biochem Biophys Res Commun 2014; 451: 171-178. doi: 10.1016/j.bbrc.2014.07.067

[26] QIU JJ, LIN YY, YE LC, DING JX, FENG WW et al. Overexpression of long non-coding RNA HOTAIR predicts poor patient prognosis and promotes tumor metastasis in epithelial ovarian cancer. Gynecol Oncol 2014; 134: 121-128. doi: 10.1016/j.ygyno.2014.03.556

[27] KIM HJ, LEE DW, YIM GW, NAM EJ, KIM S et al. Long non-coding RNA HOTAIR is associated with human cervical cancer progression. Int J Oncol 2015; 46: 521-530. doi: 10.3892/ijo.2014.2758

[28] WU J, XIE HJ. Expression of long noncoding RNA-HOX transcript antisense intergenic RNA in oral squamous cell carcinoma and effect on cell growth. Tumour Biol 2015; 36: 8573-8578. doi: 10.1007/s13277-015-3598-5

[29] WU Y, ZHANG L, ZHANG L, WANG Y, LI H et al. Long non-coding RNA HOTAIR promotes tumor cell invasion and metastasis by recruiting EZH2 and repressing E-cadherin in oral squamous cell carcinoma. Int J Oncol 2015; 46: 2586-2594. doi: 10.3892/ijo.2015.2976

[30] GAO JZ, LI J, DU JL, LI XL. Long non-coding RNA HOTAIR is a marker for hepatocellular carcinoma progression and tumor recurrence. Oncol Lett 2016; 11: 1791-1798. doi: 10.3892/ol.2016.4130

[31] WU L, MURAT P, MATAK-VINKOVIC D, MURRELL A, BALASUBRAMANIAN S. Binding interactions between long noncoding RNA HOTAIR and PRC2 proteins. Biochemistry 2013; 52: 9519-9527. doi: 10.1021/bi401085h

[32] CAI B, SONG XQ, CAI JP, ZHANG S. HOTAIR: a cancerrelated long non-coding RNA. Neoplasma 2014; 61: 379 391. doi:10.4149/neo_2014_075

[33] BETANCUR JG, TOMARI Y. Cryptic RNA-binding by PRC2 components EZH2 and SUZ12. RNA Biol 2015; 12: 959-965. doi: 10.1080/15476286.2015.1069463

[34] ZHANG SH, CHEN SL, YANG G, GU F, LI MR et al. Long noncoding RNA HOTAIR as an independent prognostic marker in cancer: a meta-analysis. PLoS One 2014; 9: e105538. doi: 10.1371/journal.pone.0105538 